\title{
ENTRE ASSIMILADOS, MULHERES E HOMENS DO MATO: A BUSCA PELO SUJEITO NACIONAL EM LUANDINO VIEIRA.
}

\author{
Among assimilated and women and men of the bush: \\ the search for the national subject in Luandino \\ Vieira.
} Washington Santos Nascimento ${ }^{*}$

\begin{abstract}
RESUMO
Este artigo se propõe a analisar as representações dos assimilados, mulheres e homens do mato nas obras produzidas pelo escritor Luandino Vieira, entre os anos de 1950 - 1970, ou que se refiram a eles. Procura-se entender de que forma ele delineia/escreve uma identidade nacional para o angolano. Para tanto analisaremos os conto "Companheiros" (escrito entre 1954 e 56 e publicado em 1960), "Vavó Xíxi e seu neto Zeca Santos" e "Estória da galinha e do ovo" (1964) e os romances "A vida verdadeira de Domingos Xavier" (1961) e "O livro dos guerrilheiros: narrativas" (2009).
\end{abstract}

Palavras chave: Identidades, Nação, Angola, Luandino Vieira.

\begin{abstract}
This article aims to analyze the representations of women assimilated and / bush men in the works produced by the Angolan writer Luandino Vieira, between the years 1950 - 1970, or referring to them. We wanted to understand how he outlines / writes a national identity for the Angolans. To this end we will analyze the tale Fellows (written between 1954 and 56 and

* Professor de História da África no Departamento de História da Universidade do Estado do Rio de Janeiro (UERJ), Maracanã. Doutor em História Social pela Universidade de São Paulo (USP). Coordenador do Grupo de Pesquisa Áfricas - Leddes/UERJ. E-mail:
\end{abstract} washingtonprof@gmail.com 
published in 1960), Grandma Xixi and grandson Zeca Santos and Story Chicken and Egg (1964) and the novels The true life of Domingos Xavier (1961) and The Book the guerrillas (2009).

Key words: Identities, nation, Angola, Luandino Vieira.

Em Angola, na segunda metade do século XX, a literatura, ou mais propriamente a fala literária, procurará superar a fragmentação da sociedade colonial defendendo a luta contra o colonialismo português e a busca por uma identidade angolana ${ }^{1}$. Este é também um dos principais traços da obra do escritor José Luandino Vieira. Filhos de pais portugueses e nascido em Portugal como José Mateus Vieira da Graça. Trazido ainda criança para Angola, morou nos bairros populares de Luanda, convivendo com aqueles que mais tarde se tornariam os protagonistas de seus livros.

Por conta de sua profunda ligação com Luanda, passou a usar como parte de seu nome o Luandino. Ligado ao Movimento Popular de Libertação de Angola (MPLA) foi preso em 1959 pelas autoridades metropolitanas portuguesa em Angola, fazendo parte do chamado "processo dos 50"2. Dois anos depois em 1961 voltou a ser preso, sendo condenado a 14 anos de prisão, cumprindo parte desta pena no campo de concentração do Tarrafal (Cabo Verde), onde escreveu a maioria de suas obras. Libertado em 1972, passou a viver em Lisboa, regressando a Angola (e Luanda) em 1974, por conta da Revolução dos Cravos em Portugal. Depois da independência em 1975 de Angola, assumiu várias frentes de atuação junto ao novo

1 A ideia de fala literária enquanto discurso, consciência de si e uma narrativa construída a partir da política, dentro e partir da literatura, é construído neste artigo a partir das leituras de Laura Padilha (2007) e Rita Chaves (1999). PADILHA, Laura. Entre voz e letra: o lugar da ancestralidade na ficção angolana do século XX. 2. ed. EdUFF, Rio de Janeiro: Pallas Editora, 2007 e CHAVES, Rita. A formação do romance angolano: entre intenções e gestos. Coleção Via Atlântica, São Paulo, 1999.

20 "Processo dos 50" é a designação encontrada para o julgamento de que se atribui à prisão e julgamento de um grupo de nacionalistas angolanos acusados de clandestinamente conspirarem contra o regime colonial português em Angola. Ao todo estiveram envolvidos no processo 56 integrantes, mas o nome "Processo dos cinquenta" se deve ao fato do padre Joaquim Pinto de Andrade ter enviado para o seu irmão que vivia no exterior, Mário Pinto de Andrade (fundador do MPLA), um folheto denunciando a prisão de 50 nacionalistas. MEDINA, Maria do Carmo. Angola. Processos Políticos da Luta pela independência, Luanda: Faculdade de Direito da Universidade Agostinho Neto. 2003 e CUNHA, Anabela Cunha. "Processo dos 50": memórias da luta clandestina pela independência de Angola, Revista Angolana de Sociologia, 8, 2011, 87-96. 
Estado como a direção da Televisão Popular de Angola, do Instituto Angolano de Cinema e da União dos Escritores Angolano.

Luandino Vieira talvez seja aquele que melhor traduziu literariamente a Luanda de meados do século XX, suas obras são marcadas por uma forte representatividade da cena luandense, apesar de escapar constantemente aos parâmetros de verossimilhança. Aspectos da história social e política da capital de Angola aparecem misturados a seus personagens; além disso, há a denúncia do colonialismo português, do processo de assimilação imposto por Portugal e por fim a busca pelo sujeito nacional, como uma "posição teórica" e "autoridade narrativa" para as vozes marginais (ou discursos de minoria) no próprio processo de pensar e imaginar a nação ${ }^{3}$.

Para Luandino este sujeito/identidade nacional nasceria do confronto/diálogo entre dois tipos de angolanos diferentes, os assimilados, mais próximos ao colonizador português, e pessoas de origens rurais, mais ligadas ao universo tradicional angolano ${ }^{4}$. Assim este artigo se propõe a discutir as representações destes dois perfis identitários nas obras produzidas por Luandino entre os anos de 1954 - 1964, no período anterior e inicial da luta armada em Angola (iniciada em 1961).

Para tanto analisaremos obras escritas dentro deste período como o conto Companheiros, escrito em 1955 e publicado no livro "A Cidade e a Infância" (1960), o romance "A vida verdadeira de Domingos Xavier", de 1961, contos "Vavó Xíxi e seu neto Zeca

3 Ao pensarmos que Angola é esta as vésperas do processo de independência nos afastamos das visões essencialistas, sobretudo se pensarmos que este processo foi também conduzido por elites nativas letradas com formação na Europa, que trabalhavam nas margens e nos entre-lugares da relação metrópole-colônia, daí a importância das questões teóricas levantadas por Homi Bhabha (1998) e Stuart Hall (2000 e 2005), analisadas e discutidas ao longo do texto. BHABHA, Homi K. O local da cultura. Belo Horizonte: UFMG, 1998; HALL, Stuart. Quem precisa da identidade? In: SILVA, Tomaz Tadeu da. (org.) Identidade e diferença: a perspectiva dos estudos culturais. Petrópolis, Rio de Janeiro: Vozes, 2000 e HALL, Stuart. A identidade cultural na pós-modernidade. 10a ed. Rio de Janeiro: DP\&A; 2005.

4 Diferentemente da norma vigente, passaremos a usar neste artigo o nome de Luandino e não Vieira, visto ser desta forma que ele é usualmente denominado e discutido pelos pesquisadores do tema, como Laura Padilha (2007) e Rita Chaves (1999) anteriormente referidas. PADILHA, Laura. Entre voz e letra: o lugar da ancestralidade na ficção angolana do século XX. 2. ed. EdUFF, Rio de Janeiro: Pallas Editora, 2007 e CHAVES, Rita. A formação do romance angolano: entre intenções e gestos. Coleção Via Atlântica, São Paulo, 1999. 
Santos" e "Estória da galinha e do ovo" de "Luuanda: estórias" de 1964 e por fim obras que se refiram a este período como em uma de suas últimas, "O livro dos guerrilheiros: narrativas" (2009), que se passa no período da luta anticolonial (1961-1975)

A análise destes contos e romances se torna importante, pois tal como Stuart Hall (1996), acreditamos que as identidades são construídas dentro e não fora do discurso, assim sendo precisamos compreendê-las como produzidas em locais históricos e institucionais específicos, no interior de formações e práticas discursivas especificas e que assim sendo são mais o produto da marcação da diferença (e da exclusão) do que signo de uma identidade idêntica e homogênea ${ }^{6}$.

\section{A assimilação colonial e os assimilados em Luandino Vieira}

$\mathrm{Na}$ história da colonização portuguesa a busca pela assimilação dos nativos foi um instrumento indispensável para a empreitada metropolitana, fazendo com que os portugueses fizessem usos de grupos locais (nativos ou não) que serviam de intermediários com as populações a serem colonizadas, pois entendiam, ao menos

5 As descontinuidades no processo de escrita de Luandino, por conta de sua própria condição de preso político, nos traz algumas dificuldades em precisar a data de escrita das obras, o que para o historiador traz com certeza alguns problemas de melhor entendimento de produção das obras, entretanto nos basearemos nas datas de escrita sugeridos por Rita Chaves (1999 e 2005) e Benjamin Abdala Junior (2007). Quanto ás edições que serão analisadas neste livro faremos uso da edição de 1981, 2006, 2007 e 2009. CHAVES, Rita. Angola e Moçambique: experiência colonial e territórios literários. Cotia/SP: Ateliê Editorial, 2005 e CHAVES, Rita. A formação do romance angolano: entre intenções e gestos. Coleção Via Atlântica, São Paulo, 1999. VIEIRA, José Luandino. A cidade e a infância. São Paulo: Companhia das Letras, 2007. 136 p., VIEIRA, José Luandino. A vida verdadeira de Domingos Xavier. São Paulo: Ática, 1981. VIEIRA, José Luandino. Luuanda: estórias. São Paulo: Companhia das Letras, 2006 e VIEIRA, José Luandino. O Livro dos Guerrilheiros. Lisboa: Caminho, 2009.

6 HALL, Stuart. Quem precisa da identidade? In: SILVA, Tomaz Tadeu da. (org.) Identidade e diferença: a perspectiva dos estudos culturais. Petrópolis, Rio de Janeiro: Vozes, 2000, p.109. 
em parte, seus códigos sociais e culturais, facilitando desta forma a atuação de Portugal nas suas colônias ${ }^{7}$.

No período em estudo neste artigo, quem fazia esse papel eram os Assimilados, eles eram angolanos que durante parte do governo salazarista português em Angola (1926 - 1974) utilizaram-se do Estatuto do Indigenato (1926 - 1961) e seus documentos complementares, para conseguirem um status legal de civilizado, dotando-os de um novo bilhete de identidade, instrumento que lhes garantiam alguns direitos, como o voto, autonomia para deslocar-se dentro da colônia, além de permitir o trabalho dentro dos segundos e terceiros escalões da administração portuguesa em Angola ${ }^{8}$.

O debate sobre a assimilação colonial e os assimilados aparece na obra "A vida verdadeira de Domingos Xavier" (1961), que se passa no momento imediatamente anterior ao início da luta armada, em 1961. Trata-se de uma narrativa sobre a realidade sócio- histórica de Angola onde se defende a necessidade da união entre angolanos de diferentes origens e mesmo portugueses solidários na luta contra o colonialismo português ${ }^{9}$. A recusa da assimilação era crucial neste contexto assim, Miguel, morador do musseque Samba, fala da importância de se ter um bilhete de assimilado naquele contexto, e da recusa em se adquirir esse estatuto ${ }^{10}$ :

7 Esta camada da população estabeleceu o que Isabel Castro Henriques (2003) chamaria de "cumplicidade contraditória" com os portugueses, auxiliando-os no processo de colonização da colônia, mas criando certa autonomia em relação à metrópole ao longo dos anos. HENRIQUES, Isabel Castro. Território e identidade. O desmantelamento da terra africana e a construção da Angola colonial (c. 1872 - c. 1926). Sumário pormenorizado da lição de síntese apresentada a provas para obtenção do título de Professor Agregado do $4^{\circ}$ Grupo (História) da Faculdade de Letras da Universidade de Lisboa. Lisboa. 2003.

8 O Estatuto Político, Civil e Criminal de Angola e Moçambique, mais conhecido como Estatuto do Indigenato, foi um documento legal promulgado pela ditadura salazarista portuguesa em 1926 até o ano de 1961. Este código legal visava organizar as relações de trabalho nas colônias africanas, bem como estipular as condições pelas quais os nativos ("indígenas") deveriam seguir para assim se tornar um assimilado ("civilizado"). NASCIMENTO, Washington Santos. Gentes do Mato: os "novos assimilados" em Luanda. Tese de Doutorado. Faculdade de Filosofia Letras e Ciências Humanas da Universidade de São Paulo, São Paulo, 2013.

9 O livro retrata a história do tratorista Domingos António Xavier, preso por ter contato com o movimento anti-colonialista em Angola, é duramente torturado e morto na cadeia, porém não denunciou ninguém. No dia de sua morte ele começara a sua vida verdadeira, na memória e nos corações de todo o povo angolano.

10 Tania Macedo (2008) afirma que “[...] musseque inicialmente designava os terrenos agrícolas arenosos situados fora da orla marítima, passando mais tarde a nomear os bairros pobres 
Era longe, da Samba até no Bairro Operário, mas a distância não lhe assustava, habituado às longas caminhadas, cruzando musseques e musseques. Temia, sim, cipaios e tropas, não tinha cartão, não tinha imposto, não tinha bilhete de identidade, nunca que quisera ter. Mas já estava muito habituado a evitar-lhes, conhecia todos os caminhos e desvios para chegar a casa de Mussunda, muitas vezes que fizera aquela caminhada. (VIEIRA, 1981, p. 65).

A opressão colonial representada pelos cipaios (espécie de soldados) e tropas, bem como as imposições legais, cartão, imposto, bilhete de identidade revela a violência existente naquele cenário urbano, no final a recusa enquanto símbolo de resistência, pois conhecia os caminhos, desvios e resistências. Nascimento (2016) em suas análises sobre o também escritor angolano Raul David, diz que naquele contexto, anos 60 - 70, anterior à independência de Angola, a recusa da assimilação era um dos nortes a partir do qual os intelectuais afirmavam ser necessário para a construção da nação angolana $^{11}$. Poderíamos, assim, entender a recusa pela assimilação, como uma posição política que era preciso ser tomada, no próprio processo de construção identitária.

Em "Luuanda: estórias" (2006 [1964]) a questão da assimilação colonial e dos assimilados aparecem, sobretudo, nos contos "Vavó Xíxi e seu neto Zeca Santos" e "Estória da galinha e do ovo". De acordo com Rita Chaves (2010), neste livro Luandino institui, conforme suas próprias palavras, uma espécie de contra-mapa da mitologia colonial, ou seja, ele coloca como protagonista das diferentes histórias os habitantes identificados com a exclusão econômica e sociocultural existente em Angola. ${ }^{12}$

situados nas franjas da cidade de Luanda" (MACEDO, 2008, p. 115). MACÊDO, Tania. Luanda, cidade e literatura. São Paulo: Editora Unesp; Luanda (Angola): Nzila, 2008.

11 NASCIMENTO, Washington Santos. Políticas coloniais e nação angolana nas memórias e discursos do escritor Raul David In: FONSECA, Danilo Ferreira; MORENO, Helena Wakim Helena; FONSECA, Mariana Bracks e NASCIMENTO, Washington Santos. Africas: política, sociedade e cultura. Edições Leddes, Rio de Janeiro, 2016 (no prelo).

12 CHAVES, Rita. A propósito da narrativa contemporânea em Angola: notas sobre a noção de espaço em Luandino Vieira e Ruy Duarte de Carvalho. In: SECCO, Carmen Tindó (et 
Os contos se passam entre os anos cinquenta e sessenta, um período em que as reuniões estavam proibidas e a tensão em toda a cidade era grande. Em "Vavó Xíxi e seu neto Zeca Santos" o protagonista Zeca, desempregado, com o pai João Ferreira preso, acusado de ações terroristas contra Portugal, vivia com a avó Xíxi. Procurava trabalho pela Baixa (então um espaço onde existia comercio popular em Luanda) e pelos musseques. Ao tentar um emprego no posto de combustíveis de Sô Souto, acaba por levar umas chicotadas do proprietário, por ser filho de um "terrorista". Tomando conhecimento através do amigo Maneco, que vira em um anúncio, sobre a possibilidade de um emprego, dirige-se até o lugar que anunciara a vaga, ocorrendo a seguinte situação:

O rapaz da farda veio nas corridas trazendo bloco de papel e lápis e parou na frente dele, à espera. O homem magro observou bem Zeca Santos nos olhos: depois depressa desatou a fazer perguntas, parecia queria-lhe mesmo atrapalhar: onde trabalhou; o que é que fazia; quanto ganhava; se estava casado; qual era a família; se era assimilado; se tinha carta de bom comportamento dos outros patrões; muitas coisas mais, Zeca Santos nem conseguia tempo de responder completo, nem nada. (VIEIRA, 2006, p. 28-29).

Nas perguntas do empregador, o trabalho, casamento, família, bilhete de assimilado e o comportamento adequado, aparecem como símbolo das boas referências para aqueles que estavam na busca de emprego. No depoimento dado pelo exassimilado Raul David, anteriormente referido, ele afirmava que no contexto colonial havia a "humilhação total do negro" e referindo-se ao pedido do bilhete de assimilado diz que o pleiteante tinha que procurar uma série de documentos: "Certidão de idade, habilitações literárias, isto é, a $4^{\mathrm{a}}$ classe, diploma, atestado de residência, atestado 
de comportamento moral e civil - dado pelo administrador do concelho" (DAVID apud NASCIMENTO, 2013, p.103-104) ${ }^{13}$. Ter "bom comportamento" significava naquele contexto cindido, não ter se insubordinado contra os portugueses. Continua o narrador a descrever sua estória ${ }^{14}$ :

- Ouve lá, pá, onde é que nasceste?

- Nasceu onde? - repetiu o contínuo.

- Catete, patrão!

O homem então assobiou, parecia satisfeito, bateu na mesa enquanto tirava os óculos, mostrando os olhos pequenos, cansados.

- De Catete, hem?! Icolibengo?... Calcinhas e ladrões e mangonheiros!... E agora, por cima, terroristas!... Põe-te lá fora, filho dum cão! Rua, filho da mãe, não quero cá catetes!... (VIEIRA, 2006, p. 29).

Catete e Icolo-Bengo são regiões do norte angolano, que estabeleceram um contato antigo com os portugueses e de onde vieram muitos daqueles que iriam fazer parte de alguns movimentos anti-colonialistas, sobretudo do Movimento Popular de Libertação de Angola (MPLA), como Agostinho Neto, primeiro presidente de Angola independente, ou ainda Adriano Sebastião e Uanhenga Xitu, membros do MPLA e embaixadores em diferentes países. Fernando Pimenta (2010) destaca que era comum entre os portugueses de Luanda, o uso da expressão "calcinhas" para os nativos que apenas recentemente tinham adotado algumas das características do modo de vida europeu (os novos assimilados por exemplo), sendo alvo de constantes de chacotas dos brancos e de uma parte substancial das antigas elites mestiça e negra europeizada ${ }^{15}$.

13 NASCIMENTO, Washington Santos. Gentes do Mato: os "novos assimilados" em Luanda. Tese de Doutorado. Faculdade de Filosofia Letras e Ciências Humanas da Universidade de São Paulo, São Paulo, 2013, p.103-104.

14 Ao longo do texto usaremos "narrador" quando disse respeito as histórias de uma determinada obra, já Luandino quando nos referirmos as posições políticas deste autor.

15 PIMENTA, Fernando Tavares. Angola. Os Brancos e a Independência. Porto: Afrontamento, 2010, p.59. Já os novos assimilados é analisado por Washington Nascimento (2013). 
Não conseguindo o emprego, restou a Zeca Santos trabalhar como carregador de sacos de cimento, agenciado por Sebastião, serviço pelo qual receberia quarenta "contos", devendo dar a Sebastião dez. No final da narrativa, Zeca, "[...] com um peso grande a agarrar-lhe no coração, uma tristeza que enchia todo o corpo e esses barulhos da vida lá fora" (VIEIRA, 2006, p. 43), chora no ombro baixo de sua avó. Lágrimas estas que só viriam a fortalecer o desejo de luta contra o colonialismo português.

No último conto do livro "Luuanda" (2006), "Estória da galinha e do ovo", a questão da assimilação aparece através de dois personagens, João Pedro Capita, mais conhecido como Azulino, e Artur Lemos. A história se passa no musseque de Sambizanga e trata do conflito entre duas vizinhas em torno de um ovo. Uma reclama a posse do ovo, uma vez que a galinha lhe pertence. Já a outra rebate dizendo que é dela porque a mesma comeu o seu milho e pôs o ovo em sua propriedade. Para ser juiz dessa contenda, diferentes personagens são chamados, mostrando assim as gradações existentes na sociedade luandense. O primeiro é Sô Zé, branco e comerciante; depois o seminarista Azulino, representante do poder clerical e da instrução; o dono das cubatas, Sô Vitalino; o ex-notário Arthur Lemos, representante da burocracia; e, por fim, o sargento e seus soldados. Assim, as diferentes faces do poder existentes em Luanda são representadas, o poder oriundo do comércio, da religião, da propriedade territorial, do Direito e por fim da força policial. Todos tentam resolver a disputa entre as mulheres em benefício próprio.

Azulino e Arthur Lemos são os únicos angolanos instados a serem juízes no processo, por serem eles assimilados às estruturas coloniais. Assim sendo, em Luandino (2006), há uma forte crítica aos dois assimilados, Azulino é assim descrito:

A fama de Azulino era grande no musseque, menino esperto como ele não tinha, mesmo que só de dezasseis anos não fazia mal, era a vaidade de mamã Faxi, o sô

NASCIMENTO, Washington Santos. Gentes do Mato: os "novos assimilados" em Luanda. Tese de Doutorado. Faculdade de Filosofia Letras e Ciências Humanas da Universidade de São Paulo, São Paulo, 2013. 
padre do Seminário até falava ia lhe mandar estudar mais em Roma. E mesmo que os outros monas e alguns maisvelhos faziam-lhe pouco porque o rapaz era fraco e com uma bassula de brincadeira chorava, na hora de falar sério, tanto faz é latim, tanto faz é matemática, tanto faz é religião, ninguém que duvidava: Azulino sabia. (VIEIRA, 2006, p. 117).

A ligação de Azulino com o universo cultural e simbólico europeu e cristão é enfatizado através da forma como ele tenta resolver a contenda, fazendo uso da história bíblica da moeda e da frase "a César o que é de Cesar". Ao estar com o ovo em suas mãos, diz:

- Nem a imagem de César, nem a imagem de Deus!

Levantou os olhos gastos atrás dos óculos, mirou cada vez Zefa e Bina, concluiu:

- Nem a marca da tua galinha, Zefa; nem a marca do teu milho, Bina! Não posso dar a César o que é de Cesar, nem a Deus o que é de Deus. Só mesmo padre Júlio é que vai falar a verdade. Assim... eu levo o ovo, vavó Bebeca! (VIEIRA, 2006, p. 118).

Em sua fala a logica cristã e referências a símbolos europeus como os óculos. Por fim, o que é mais significativo, ou seja, só o padre era detentor da verdade, aquele que traria a claridade para aquela situação. Azulino é obstaculizado por Nga Zeza: “- Sakuama! Já viram? Agora você quer levar o ovo embora no Sô padre, não é? Não, não pode! Com a sua sapiência não me intrujas, mesmo que nem sei ler nem escrever, não faz mal! "(VIEIRA, 2006, p.118).

O segundo assimilado da trama é sô Arthur Lemos, exnotário e agora um dependente de álcool. Era desta forma, como salienta Adriana Mello Guimaraes (2012), o símbolo da burocracia, bem como da decadência do sistema colonial. É assim descrito pelo narrador (2006): 
É que a vida dele era tratar de macas. Antigamente, antes de adiantar beber e estragar a cabeça, sô Artur Lemos trabalhava no notário. Na sua casa podiam-se ainda encontrar grossos livros encadernados, processo penal, processo civil, boletim oficial, tudo, parecia era casa de advogado. E as pessoas, quando queriam, quando andavam atrapalhadas com casos na administração, era sô Arthur que lhes ajudava. (VIEIRA, 2006, p. 123).

Arthur Lemos, por ter acesso ao mundo do Direito metropolitano, servia de intermediário entre os angolanos e portugueses. Assim Luandino (2006) ressalta, tal qual outros personagens que viveram aquele contexto, como o português Adriano Moreira em "As elites das províncias portuguesa de Indigenato (Guiné, Angola, Moçambique)" e o angolano Raul David, anteriormente referido, o papel de intermediários exercidos pelos assimilados. Vejamos como Arthur Lemos tenta resolver o problema:

- Diz a senhora que a galinha é sua?

- Sim, sô Lemos.

- Tem título de propriedade?

- Ih? Tem é o quê?

- Título, dona! Título de propriedade! Recibo que prova que a galinha é sua!

Nga Zefa riu:

- Sukuama! Ninguém no musseque que não sabe a Cabíri é minha, sô Lemos. Recibo de quê então?

- De compra, mulher! Para provarmos primeiro que a galinha é tua!

- Possa! Esse homem... Compra?! Então a galinha me nasceu-me doutra galinha, no meu quintal, como é vou ter recibo?

Sem paciência, sô Lemos fez sinal para ela se calar e resmungou à toa:

- Pois é! Como é que as pessoas querem fazer uso da justiça, se nem arranjam os documentos que precisam? (VIEIRA, 2006, p. 125) 
$\mathrm{Na}$ forma como Arthur Lemos age, Luandino (2006), evidencia a importância da burocracia enquanto elemento de diferença social dentro de Luanda, distante das lógicas sociais próprias dos angolanos. Em sua discussão sobre o imperialismo europeu Hannah Arendt (2009) diz que ela, junto com a raça, foram importantes mecanismos de organização política e de domínio dos povos colonizados, sendo a burocracia a base organizacional do jogo de expansão e controle dos povos recém dominados ${ }^{16}$.

Voltando ao conto, ele termina com a intromissão dos dois garotos e a resolução da contenda, dando o ovo para a mulher grávida, reforçando assim o sentimento de solidariedade entre o povo do musseque, bem com a ideia de que se estava a gestar um novo momento, uma nação independente de Portugal, a qual não seria construída sem a existência de uma "camaradagem horizontal" e sem o auxílio da juventude ${ }^{17}$.

A verdade no processo certamente não está do lado dos portugueses/representantes do colonialismo Zé-branco, Vitalino e os soldados. Também não estava como os assimilados (Arthur Lemos e Azulino) porque, como salienta José Ornelas (1990), eles faziam parte do texto do colonizador ${ }^{18}$. A verdade estava do lado dos colonizados, das pessoas do musseque, dos jovens e sobretudo das mulheres que como atesta Marilucia Ramos (2014) mostram que [...] apesar das diferenças e rusgas, a ideia de pertencimento a um grupo aflorava, assim como a necessidade de assumir um papel de protagonismo naquele cenário opressor (RAMOS, 2014, p.26-27) ${ }^{19}$.

Em obras mais recentes, como "O livro dos guerrilheiros: narrativas" (2009), que se passa no período da luta anticolonial

16 ARENDT, Hannah. Origens do totalitarismo. São Paulo, Companhia das Letras, 2009 , p. $215-216$.

17 A ideia da necessidade de uma "camaradagem horizontal" no processo de imaginar a nação é tributária a Benedict Anderson (2008, p.13). ANDERSON, Benedict. Comunidades imaginadas: reflexões sobre a origem e a difusão do nacionalismo. São Paulo: Companhia das Letras, 2008.

18 ORNELAS, José. Luandino Vieira: A desconstrução do discurso colonial In: Letras de Hoje, numero 80, PUCRS, Junho de 1990, p. 73.

19 RAMOS, Marilúcia Mendes. Imagens de Angola nas representações do feminino em narrativas angolanas In: SILVA, Fabio Mario. O Feminino nas Literaturas Africanas em Língua Portuguesa. Centro de Literaturas e Culturas Lusófonas e Europeias, Faculdade de Letras da Universidade de Lisboa. Lisboa, 2014. 
(1961-1975) e que mistura romance com memórias do autor, é possível perceber a alusão aos assimilados quando cinco exguerrilheiros contam suas "memórias". O primeiro "depoente", guerrilheiro Celestino Sebastião (Kakinda), dá uma entrevista à televisão portuguesa na qual relembra sua entrada na luta armada e os cincos combates em que participara. O primeiro em 1939, o segundo em 1948, o terceiro em 1951, o quarto em 1959 e o quinto em 1961. No relato do quarto combate é possível perceber a presença de assimilados em Luanda e seu papel na luta anti-colonial:

Quarto combate é na Pascoa de 59. Eu era marceneiro nas oficinas do Banco de Angola, um Luuanda. Fazia só meu trabalho, de quieto e calado. Sonhava voltar na roça minha, no Tenda Rialozo. Meu nome era João Palmeirim, me disfarcei de meu mestre. No clandestino da oficina fiz um copiógrafo, usava gelatina e tinta roxa, um amigo trouxe receita numa revista de crianças. Esse amigo era um assimilado, trazia também panfleto quando saía. Eu só fazia minhas cinco copias, para distribuir eu mesmo. Um dia me despediram sem mais nem quê: que era amigo de mulatos e assimilados, músicos. Se queriam ser calcinhas como eles? Insultaram-me de político da merda, com muita sorte. Fugi de Luanda na madrugada do 6 de Fevereiro de 61, meu patrão Palmeirim me deu a boléia. (VIEIRA, 2009, p. 20).

Em sua fala a associação dos assimilados ao universo da escrita e a importância dos textos escritos como mais uma forma de resistência ao colonialismo português, afinal os panfletos também foram elementos a guerra subterrânea (clandestina) que antecede a luta armada, gerando prisões e o chamado "processo dos cinquenta", uma das primeiras devassas feita pelo colonialismo português em Angola contra os ativistas anti-coloniais, sendo o Luandino Vieira um dos partícipes. Há também referências aos músicos, também citados em "A Vida verdadeira...", sobretudo o Ngola Ritmos, que funcionava como uma espécie de arquétipo de união/identidade angolana, pois cantavam tanto em Português, quanto em quimbundo. 
Ruy Mingas, um dos membros deste grupo destaca que "[...] a inciativa do "Ngola Ritmos" em cantar em quimbundu representava já a busca ou o oferecer à sociedade uma mensagem musical com alguma identidade que era cantar no nosso quimbundu" (MINGAS apud ALVES, 2015, p.88) ${ }^{20}$.

$\mathrm{Na}$ narrativa do segundo guerrilheiro, Eme Makongo, o relato de que seu comandante tinha sido um assimilado, e que por esta razão durante a luta anticolonial pós 61 tornara-se mais maleável, respeitando dessa forma determinadas atitudes de seus comandados, como andar descalço, cheirar o chão, a mata e ar para evitar as minas nas picadas. Por outro lado, mesmo sendo assimilado, de origem urbana, aceitava e não contrariava determinadas atitudes daqueles que habitavam, viveram ou tinham vindo do mato.

\section{O mundo natural e as mulheres e homens do mato}

Para Portugal o "mato" não era um território com fronteiras delimitadas, mas sim o longe e periférico, o não urbano, não civilizado, cenário da colonização propriamente dita. Como salienta Diego Marques (2012) para a narrativa colonial portuguesa era o locus da "existência recidiva" e "bruta" dos da terra". Aqueles que vinham desta região eram chamados em Luanda de matumbos, uma variação da palavra kimbundu matumbu que, segundo Oscar Ribas (2009), passou a designar "Indivíduo bastante atrasado, ainda não liberto dos costumes primitivos. Selvagem. Ignorante. Bisonho. Fig. Incivil. Acanhado. Inexperiente" (RIBAS, 2009, p. 306). Por outro lado, para os angolanos poderia ser onde as tradições se faziam

20 ALVES, Amanda Palomo. "Angolano segue em frente": um panorama do cenário musical urbano de Angola entre as décadas de 1940 e 1970. Tese de Doutorado. Programa de Pós Graduação em História. Universidade Federal Fluminense, 2015.

21 MARQUES. Diego Ferreira Marques. O carvalho e a mulemba: Angola na narrativa colonial portuguesa. Tese de Doutorado. Programa de Pós graduação em Antropologia Social. Universidade Estadual de Campinas. 2012. 
presentes e onde se poderia encontrar o verdadeiro homem angolano ${ }^{22}$.

Apesar de ser um escritor profundamente ligado a Luanda e suas histórias, a referência ao "mato" ou interior e as pessoas vindas desta região são comuns nas obras de Luandino como no conto "Companheiros", escrito em 1954 e publicado em "A Cidade e a Infância" seu livro de estreia. A história se passa em Huambo (então denominada de Nova Lisboa) e constitui-se enquanto uma alegoria das distinções existentes entre as camadas mais pobres de Angola, ou seja, diferenças raciais e de origem ${ }^{23}$. O negro é representado por Negro João, o mulato por Armindo mulato e as pessoas do interior por Calumango rato do mato! No conto de Vieira é possível entender a associação do negro, mulato e mato ao nome das personagens enquanto construção de um lugar social cujo propósito é o de exemplificar uma série de relações sociais existentes então em Angola. Para Pierre Bourdieu (2007) a imposição de um nome reconhecido faz com que se opere uma verdadeira transmutação da coisa nomeada que, desta forma torna-se uma função social, ou seja, uma missão, um encargo, um papel, assim todos tinham uma funcionalidade social nesta obra ${ }^{24}$.

Negro João é apresentado como ingênuo, originário do musseque, filho do capim, vendedor de jornais nas esquinas de Huambo, calado, partilhando com Armindo e Calumango os dividendos do dia. Aprendera a ler com Armindo, um mulato de Luanda, que trouxera consigo a malandragem e a leitura, que tentava ensinar para João e Calumango ${ }^{25}$. A mãe de João prostituía-se, o pai, um português casado com uma branca vinda de Portugal ainda o

22 Esta é uma das questões destacadas sobretudo pelos escritores Raul David e Uanhenga Xitu em suas diferentes obras, a exemplo de Colonizadores e Colonizados de Davi e Kahitu de Xitu. DAVID, Raul. Colonizadores e Colonizados. Porto, Edições 70, 1984 e XITU, Uanhenga. Vozes na Sanzala (Kahitu). Luanda. Edições Maianga, 2004.

23 O Huambo é uma cidade e município em Angola, sede da Província do Huambo. Durante parte do período colonial (1928 e 1975) era chamada pelos colonizadores de Nova Lisboa, entretanto Luandino conserva e usa o nome nativo Huambo, mesmo tendo seu conto se passado entre os anos 40-60.

24 BOURDIEU, Pierre. A distinção: crítica social do julgamento. São Paulo: Edusp; Porto Alegre: Zouk, 2007, p.444.

25 A expressão filho do capim refere-se aos angolanos frutos de uma relação não consensual entre portugueses e nativos. 
manteve por um tempo na escola, mas a perversidade de sua madrasta o fez sair de casa e o empurrou para o musseque. Vivera entre as noitadas da periferia de Luanda, as praias e do mar, sobre o qual ouvira de seu primo marinheiro muitas histórias, que recontava para João e Calumango. Salvato Trigo (1981) diz que Armindo era o chefe daquela "[...] micro-sociedade de lumpen-proletariado que o sistema colonial criava à medida em que o urbanismo, que instaurava e instituía, atraía para as cidades jovens do mato (TRIGO, 1981, p.311312).

Calumango viera do interior (o "mato") e trabalhava como engraxate nas ruas de Huambo. Um "matumbo", nas palavras de Armindo, ainda sem prática em seu oficio, se espantava com a cidade, não tinha ainda a malandragem de um Armindo que o ensinava a ler, mas também a fazer mais brilho com menos graxa. $\mathrm{O}$ narrador descreve Calumango enquanto este ouve as histórias de Armindo:

Calumango olhava e bebia as palavras. Os olhos pequenos e receosos de animal do mato dilatavam-se. Cheirava à terra, a terra estava no seu corpo. As anharas extensas. A lavra de milho, da mandioca. A tentação da cidade também o tocara: não resistira ao chamado das bugigangas, dos panos coloridos da loja do sô Pinto. A irmã também não resistira: dormia com o sô Pinto. (VIEIRA, 2007, p. 94).

O medo da cidade grande, a ligação com a terra e a tentação da cidade são traços aos quais Luandino (2007) constrói Calumango, enquanto uma alegoria do homem do mato. Na distinção entre Armindo e Calumango, o mar (Luanda) e o mato, enquanto elementos opostos, o mato desejando o mar descrito por Armindo: "E Calumango, rato do mato, vê o mar. É assim como nos dias de vento o capim a dançar na anhara. Sente que é assim" (VIEIRA, 2007, p. $95)^{26}$. Antônia de Sousa Neto \& eu (1981). Laurentino, protagonista do primeiro conto, diz sentir uma 
Deixar de ser "matumbo" para ser homem de verdade passava, na visão de Armindo, por aprender a malandragem de Luanda, por isso foi junto com Armindo e Negro João roubar o interior de alguns veículos. Pego, Armindo apanhou sozinho do policial e protegeu Calumango e João dizendo para que eles fossem embora, que não poderiam fazer mais nada:

Calumango calado, o olhar receoso acompanhando o amigo que não tinha medo dos polícias nem do cassetete. Nem gritava quando lhe batiam. Sentiu qualquer coisa dentro de si partir-se. Os punhos cerraram-se. Não era mais Calumango, rato do mato! Não era mais! Na outra esquina, a mão livre num adeus camarada, Armindo mulato, do corpo gingadão, dos ditos malandros, sorria para trás. (VIEIRA, 2007, p. 98).

Em Luandino (2007) é possível perceber que a opressão colonial diluía o mato dentro da cidade. Como faz referência o título do conto, agora todos eram "companheiros", construía-se dessa forma uma nova identidade, a partir do mulato, ou seja, uma identidade única, mestiça e também crioula. Segundo Filipe Morais (2007) esta seria então "[...] uma identidade para se rebelar, uma identidade para que vale a pena arriscar-se um pouco mais. Uma identidade que apesar do risco, vale a pena não ter medo" (MORAIS, 2007, p. 37$)^{27}$.

Em “A Vida Verdadeira de Domingos Xavier" (1961), analisada anteriormente, onde é descrita a história de Domingos Xavier, um tratorista luandense que trabalhava em diferentes lugares do interior angolano e que, no momento do conto, participava da

enorme saudade de Luanda, andando na boléia de um caminhão por Angola, diz "Angola é grande, irmão! - nuvens de Kinaxixi nunca mais via, viagem ia: de tudo, um verso ficou, refrão de ainda sempre que nossas riquezas vejo por aí: 'Come e arrebenta, o que sobra vai no mar' Viemos - eu querendo ouvir o gosto do sal no ar das matas" (VIEIRA, 2004, p. 31). VIEIRA, Luandino. Laurentino, Dona Antônia de Sousa Neto \& eu. Luanda: Edições Maianga, 2004.

27 MORAES, Filipe. Uma análise sobre os aspectos marcantes das identidades do tempo (a infância) e do espaço (a cidade) "presente" nas estórias da obra A Cidade e a Infầncia, de José Luandino Vieira. In: O Cabo dos Trabalhos: Revista Electrónica do Programa de Doutoramento Pós-Colonialismos e Cidadania Global, Lisboa, No 2, 2007, p. 1- 47. 
construção de uma barragem no Dondo ${ }^{28}$. É preso e torturado para que entregasse alguns de seus companheiros (sobretudo o branco, traidor) que estavam lendo livros "subversivos" e articulando-se politicamente contra o regime português. O jogo mato e cidade aparece na história central do conto. Mario Pinto de Andrade, em um texto de 1977, evidencia esta relação:

[...] um preso, proveniente do mato, conduzido por dois cipaios, chega ao posto da polícia do musseque. As pesquisas feitas por seus compatriotas para o identificarem (dar um nome a esta face inchada e espancada) vão revelar progressivamente as malhas profundas da solidariedade militante que alimenta o movimento nacionalista (ANDRADE, 1977, p. 222) . $^{29}$.

O mato e a cidade ligados pela exploração colonial, pela violência do colonizador e pelos laços entre todo o povo angolano na luta pela independência. No conto, uma miscelânea de personagens representativos do povo angolano que se insurgia contra o colonialismo português; o operário Domingos Xavier, o autônomo Mussunda, o burocrata Xico, o branco Silvestre... o mato é representado por Maria, mulher de Domingos Xavier ${ }^{30}$.

Maria nascera no musseque Braga, mas há doze anos tinha ido viver no interior angolano, aprendera e conservara alguns hábitos aprendidos no mato, como é possível perceber na passagem em que

28 Atualmente o Dondo é uma cidade de Angola, sede do município de Cambambe, na província de Cuanza Norte. Em depoimento dado a Michel Laban (1980) Luandino Vieira diz: “[...] trabalhei na barragem de Cambambe. Gosto de dizer isso porque $A$ Vida Verdadeira de Domingos Xavier passa-se em Cambambe e, em grande parte, o que se lá conta passou-se, e, salvo os nomes, que estão alterados, as pessoas existiram" (VIEIRA In LABAN, 1980, p. 16). LABAN, Michel (et alli). Luandino, José Luandino Vieira e a sua obra: estudos, testemunhos, entrevistas. Lisboa : Edições 70, 1980.

29 ANDRADE, Mário Pinto de. Uma nova linguagem no imaginário angolano. In: LABAN, Michel (Org.) Luandino: José Luandino Vieira e sua obra. Lisboa: Edições 70, 1977. p. $220-227$.

30 Valdemir Zamparoni (1993) confere a Maria o papel de "mulher casada" na representação que faz. ZAMPARONI, V. D. . Ficção e História em A Vida Verdadeira de Domingos Xavier. Polifonia (UFMT), Cuiabá, v. 01, p. 160-180, 1993. 
ela chega a mais um posto administrativo nos Musseques, o posto dos musseques, à procura de Domingos: "No imbondeiro, de folhas novas, pírulas cantavam chuva e Maria, ouvindo-lhes, olhou novamente o céu, hábito de gente do mato". (VIEIRA, 1981, p. 55). A distinção entre cidade e mato aparece na fala de Maria quando começa a chover em Luanda:

Maria pensava a chuva, estava cheirar a chuva que vinha, e os grandes campos do planalto apareciam nos seus olhos, em baixo duma cortina de água alagando tudo, mas depois verdejava o capim, o milho, o massango, a massambala. Não sabia como era a chuva nesta cidade e nem podia pensar ainda a água ia molhar naquele alcatrão. Na sua imaginação, ali, em Luanda, a chuva só ia cair no mar ou nas ruas dos musseques, não podia mesmo cair no sítio ocupado por essas casas bonitas dos brancos, com seus grandes jardins. (VIEIRA, 1981, p.59$60)$.

O cheiro da chuva, a referência ao alcatrão, asfalto de rua largamente utilizado na parte nobre de Luanda são destacados por ela. A chuva era o elemento que trazia o mato para dentro da cidade. Em outra passagem do livro Maria se depara com um enorme dilúvio e novamente ressalta as diferenças entre os universos do asfalto (a cidade) e da areia (o mato), mas também a distinção entre cidade e musseque:

Maria assistia, admirada, via a cidade toda coberta de água, chovia parecia era nas anharas do planalto e nem havia areia para beber a água. Ali só os carros passavam, a água corria barulhenta em baixo dos pneus. Chuva, raios que brilhavam toda a tarde cinzenta, trovões estremecendo vidros e os corações do povo lá em cima, metido em suas casas de barro e canas, cobertas a zinco, assistindo o barro a se desfazer. (VIEIRA, 1981, p. 62). 
A chuva fizera Luanda voltar a ser a cidade que Maria tinha conhecido, representada arquetipicamente pelas anharas. A anhara é uma palavra em quimbundo que significa uma planície arenosa, de vegetação rasteira, que margeia um rio, muito comum em parte significativa do interior angolano. Agora Luanda para ela era desconhecida e muito diferente daquela cidade de sua infância, sobretudo pelas mudanças na estrutura urbana da cidade. Nascimento (2016), destaca que entre os anos quarenta a sessenta do século XX, com a chegada em massa dos portugueses e de angolanos do interior, a capital de Angola passará por um remodelagem urbana significativa com a expulsão das populações nativas do centro e uma verticalização urbana mais acentuada dos principais bairros ${ }^{31}$.

Para achar Domingos, que tinha sido preso pelos agentes coloniais, naquela cidade nova teria que aprender algumas "malandragens", levar seu filho para comover os agentes, "fazer barulho", "chorar", "berrar". Além da malandragem, tivera que aprender em Luanda a resiliência, representada por Tété, "[...] mulher do povo, vivendo na vida do musseque de Luanda, sempre sofrendo, lhe dera essa maneira de ver todas as coisas sem nunca desistir" (VIEIRA, 1981, p. 58-59).

Tal qual em outras obras analisadas, a referência de Luanda com o mar aparece também nesta. Maria, doze anos afastada de Luanda, crescida no mato, enquanto esperava o velho maximbondo ${ }^{32}$, vê o mar, [...] lá em baixo, na Baía, os grandes barcos escuros parados, as águas virando de azul bonito para cinzento" (VIEIRA, 1981, p. 59). O mato, enquanto um sertão, afastado do mar.

O destino de Maria foi o mesmo de todos os angolanos sob o colonialismo português, a violência, a morte de seu companheiro torturado na cadeia... enfim, o jugo colonial que afastava todo o povo angolano, indistintamente, de suas origens e trajetórias. Nesse sentido é a mesma ideia presente no conto "Companheiros", anteriormente analisado: a criação de uma identidade política única (o colonizado) para lutar contra o colonizador e a busca da nação como forma de

31 NASCIMENTO, Washington Santos. Das Ingombotas ao Bairro Operário Políticas metropolitanas, trânsitos e memórias no espaço urbano luandense. (Angola, 1940-1960). Revista Locus, 2016.

32 Uma espécie de Ônibus comum em Luanda. 
preencher o vazio deixado pelo desenraizamento de sua comunidade de origem (no caso de Maria) os dos laços de parentesco (em Companheiros).

Desta forma, através de suas obras, Luandino constrói, o que Hall (2005) chama de narrativa da nação, ou seja, uma serie de estórias, comportamentos, cenários, símbolos e rituais que simbolizam ou mesmo representam as experiências partilhadas, as perdas, os triunfos e os desastres que dão sentido a nação ${ }^{33}$.

\section{Considerações Finais}

O conceito de identidade talhado por Luandino era, sobretudo, estratégico e posicional em relação a própria situação colonial, ou seja, construído por meio da diferença e não fora dela. Assim sendo, o processo de construção do sujeito nacional passaria pela negação da assimilação colonial e pela força de um elemento novo naquela sociedade colonial que era o empoderamento feminino. Por outro lado teria que haver também uma busca daquilo que poderíamos chamar de mais tradicional em Angola, ou seja, o homem/mulher do mato, ligado a natureza e a raízes profundas.

Para entender esta aparente contradição entre o "novo" (a recusa da assimilação, o poder das mulheres) com o "antigo" (ligação com o tradicional, a natureza) precisamos voltar novamente a Bhabha (2007) para quem a ideia de povo no processo de construção (ou escritura) da nação pressupõe por um lado um tipo de pedagogia nacionalista que se baseia no passado, no pré-estabelecido, na origem histórica e por outro na construção de "sujeitos" que devem obstaculizar/suprimir qualquer presença anterior ou originária ${ }^{34}$. Assim, é através deste processo ambivalente de continuidade-ruptura

33 HALL, Stuart. A identidade cultural na pós-modernidade. 10a ed. Rio de Janeiro: DP\&A; 2005, p. 52 .

34 BHABHA, Homi K. DissemiNação: o tempo, a narrativa e as margens da nação moderna. In: BHABHA, Homi K. O local da cultura. Belo Horizonte: UFMG, 1998, p.198-238. 
que se escreve/dissemina a nação, onde assimilados, mulheres e homens do mato, são também parte do processo construção do estado pós-colonial.

RECEBIDO EM: 22/11/2015

APROVADO EM: 03/05/2016 